\title{
Power loss due to Corona on High Voltage Transmission Lines
}

\author{
Enesi Asizehi Yahaya ${ }^{1}$, Tsado Jacob ${ }^{2,}$ Mark Nwohu ${ }^{3,}$ Ahmed Abubakar ${ }^{4}$. \\ ${ }^{I}$ Departmt of Electrica and Electronics Engineering. Federal University of Technology, PMB 65, Minna, \\ Nigeria
}

\begin{abstract}
The effect of corona on high-voltage transmission lines is one of the causes power loss and this is uneconomical and undesirable. The study of corona and factors responsible for the loss is investigated through sample calculation based on Peek's formula and the results are then simulated through matlab program. This paper presents the relations between power loss due to corona to corona parameters through matlab programs and suggests some possible steps taken to minimize corona loss.
\end{abstract}

Keywords: Corona, power loss, peek's formula, high voltage transmission lines, Peek's formula.

\section{INTRODUCTION}

When in an insulation system, the voltage gradient (voltage stress) exceeds a critical voltage, the air molecules surrounding the high voltage transmission line conductors become ionized (transient gaseous ionization) resulting in partial discharges. Corona loss occurs if the line to line voltage exceeds the corona threshold. The conductive region is not high enough to cause electrical breakdown or arcing to any nearby objects [1]. Corona can occur within voids of an insulator, at the conductor or at the insulator interface. Rough surfaces are more liable to corona because the unevenness of the surface decreases the value of the breakdown voltage. It can be detected due to its visible light in form of purple glow consisting of micro arcs and its sound can be heard through its hissing and cracking sound [2]. The smelling of the presence of ozone production is noticed during corona activity [3]. The effects of corona are cumulative and permanent and the failure can occur without warning. In insulation system, corona discharges result in voltage transients. The effects of corona associated with the operation of high voltage transmission lines include radio interference, audible noise, gaseous effluents (Ozone and Nitrogen oxide) and shock potential. Conductor voltage, diameter and shape, dusts, water drops, and surface irregularities such as scratches are factors that affect the performance and conductor's electrical surface gradients. The energy loss due to corona is transformed into sound, radio noise, chemical reactions of the air components and heat [4]. Corona reduces the reliability of insulation system thereby degrading insulation and causes system failure due to dielectric breakdown. The study becomes necessary because of the prevailing negative effect of corona parameters on the power loss of high voltage transmission lines. The power loss under fair weather conditions and under stormy weather conditions when investigated, analyzed and simulated using matlab programs gives the results which help us to take necessary measures to minimize the power loss under fair and stormy weather conditions. High quality insulated and good service design underground high transmission cables can help to eliminate the loss due corona effect The advantage of corona is that the sound generated during corona activity can be used to build high accuracy audio speakers and also it has no mass to be moved to create the sound so that transient response is improved. The controlled corona discharge can be used for filtrations and printing.

\section{Power Loss}

According to Peek's formulas [5], the power loss due to corona under fair weather conditions can be expressed as:

$$
P_{u f w c}=\frac{K}{\delta}(f+25) \sqrt{\frac{R}{d}}\left(\frac{V_{L}}{\sqrt{3}}-E_{d c v}\right)^{2} L \times 10^{-5} \mathrm{KW} / \mathrm{km} / \text { phase }
$$

The normalized air density correction factor, $\delta$ is 1 at $25^{\circ} \mathrm{C}$ at $76 \mathrm{~cm}$ pressure. Table 1 shows the sample of corona loss calculation based on peek's formula 
Under the stormy weather conditions, the disruptive critical voltage $\left(\mathrm{E}_{\mathrm{dcv}}\right)$ is taken as 0.8 times that of the fair weather value. Where the ratio of the phase voltage to the disruptive critical voltage is less than 1.8 , Peterson formula [6] is used for determining the corona loss. This is given as:

$$
P_{p e t}=\frac{21 \times 10^{-6} \times f V^{2}}{(\log 10 d / R)^{2}}
$$

Table 1. Sample corona loss calculation based on Peek's formula.

\begin{tabular}{|c|c|c|}
\hline Symbol & parameter & Sample value \\
\hline $\mathrm{K}$ & Fixed constant & 243 \\
\hline $\mathrm{D}_{\mathrm{ga}}$ & Disruptive gradient in Air & $21.2 \mathrm{kv} / \mathrm{cm}$ \\
\hline$m_{d}$ & Irregularity factor for disruptive critical voltage & 0.85 \\
\hline $\mathrm{m}_{\mathrm{v}}$ & Irregularity factor for visual corona inception voltage & 0.72 \\
\hline $\mathrm{t}$ & Temperature of the surroundings & $45^{0} \mathrm{C}$ \\
\hline $\mathrm{P}$ & Atmospheric pressure & 750 torr \\
\hline$\delta$ & $\begin{array}{l}\text { Air density correction factor: } \\
\delta=\frac{0.386 P}{273+t}\end{array}$ & 0.9104 \\
\hline $\mathrm{R}$ & Radius of conductor & $0.54 \mathrm{~cm}$ \\
\hline $\mathrm{d}$ & Conductor spacing & $300 \mathrm{~cm}$ \\
\hline f & frequency & $50 \mathrm{~Hz}$ \\
\hline $\mathrm{V}_{\mathrm{L}}$ & Line to line voltage & 132 \\
\hline $\mathrm{E}_{\mathrm{dcv}}$ & $\begin{array}{l}\text { Disruptive critical voltage: } \\
\mathrm{D}_{\mathrm{ga}} \delta \mathrm{m}_{\mathrm{d}} \mathrm{R} \log (\mathrm{d} . / \mathrm{R})\end{array}$ & $55.98 \mathrm{kv}$ to Neutral \\
\hline $\mathrm{E}_{\mathrm{vcv}}$ & $\begin{array}{l}\text { Visual inception corona voltage: } \\
\mathrm{D}_{\mathrm{ga}} \delta \mathrm{m}_{\mathrm{v}} \mathrm{R} \log (\mathrm{d} . / \mathrm{R})(1+0.3 . / \operatorname{sqrt}(\delta \mathrm{R}))\end{array}$ & $67.72 \mathrm{kv}$ to Neutral \\
\hline $\mathrm{L}$ & Length of the conductor & $100 \mathrm{~km}$ \\
\hline$\overline{P_{\text {ufwc }}}$ & Corona loss under fair weather conditions & $347.37 \mathrm{kw} / \mathrm{phase}$ \\
\hline $\mathrm{P}_{\text {uswc }}$ & Corona loss under stormy weather conditions & $838.53 \mathrm{kw} / \mathrm{phase}$ \\
\hline
\end{tabular}

\section{Effects Of Corona Parameters On Power Loss Due To Corona}

\subsection{Atmospheric conditions like pressure and temperature}

Corona loss is a function of Air density correction factor and the higher the value, the less the corona loss. At low pressure and high temperatures, the value of disruptive critical voltage is small and corona effect and loss is dominant [7].

\subsection{The inception corona voltage and the disruptive critical voltage}

The visual inception corona voltage is more than the disruptive critical voltage because its formation involves ionization and the raising of electron to an excited state. This excitation produces light by discharge and other electromagnetic waves [8,9,10]. Figure 1 shows the graphical comparation of the visual and disruptive corona voltage at various radii of the conductor. The conductor radius is directly proportional to both visual corona voltage and disruptive critical voltage 


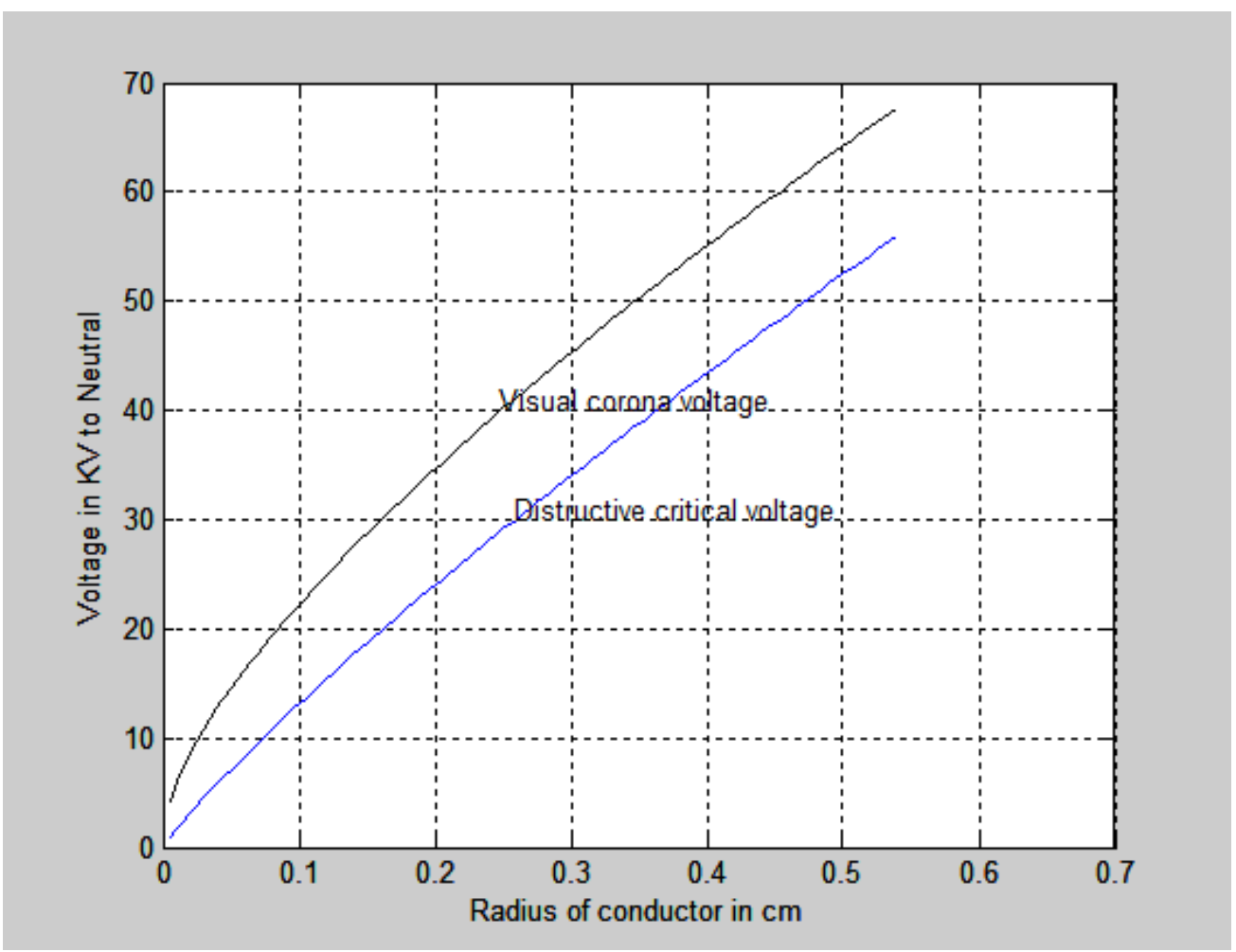

Fig. 1: corona voltage at different value of conductor radius

\subsection{Spacing between conductors}

Figure 2 shows that under fair weather condition at various spacing between the conductors. Corona loss is inversely proportional to the spacing between conductors. If the spacing is made to be very large, corona loss may be absent.

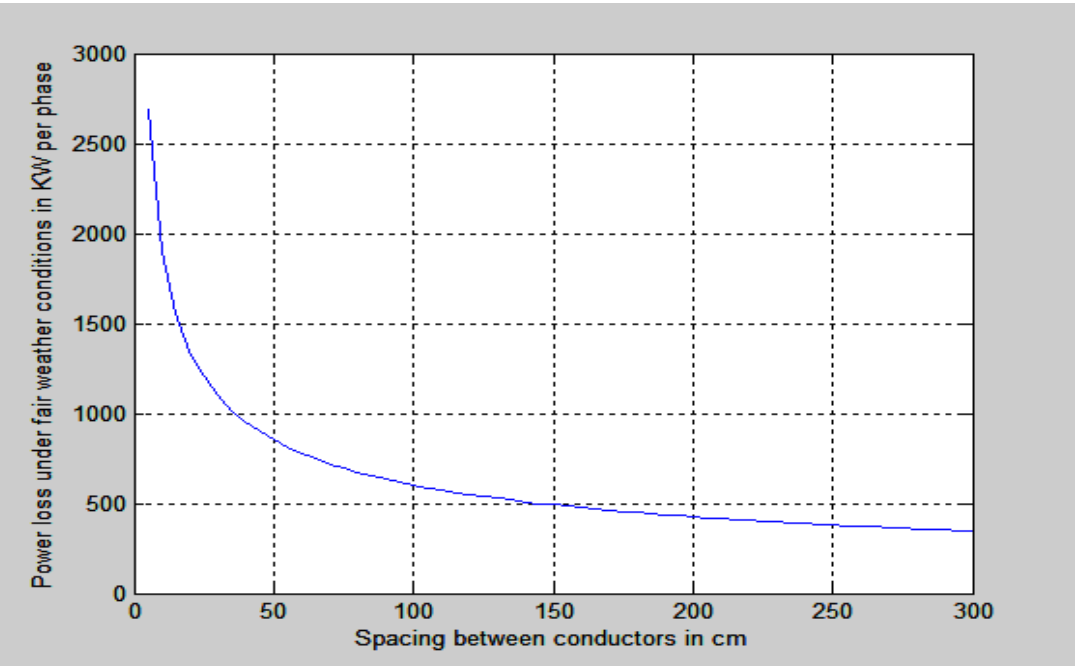

Fig. 2: power loss due to corona loss versus the spacing between conductors

\subsection{The supply frequency}

Figure 3 shows that the higher the supply frequency, the higher the corona loss. The d.c. corona loss is less than that of a.c corona loss. The effect of corona on a.c. lines generates third harmonic components that increase the corona loss. 


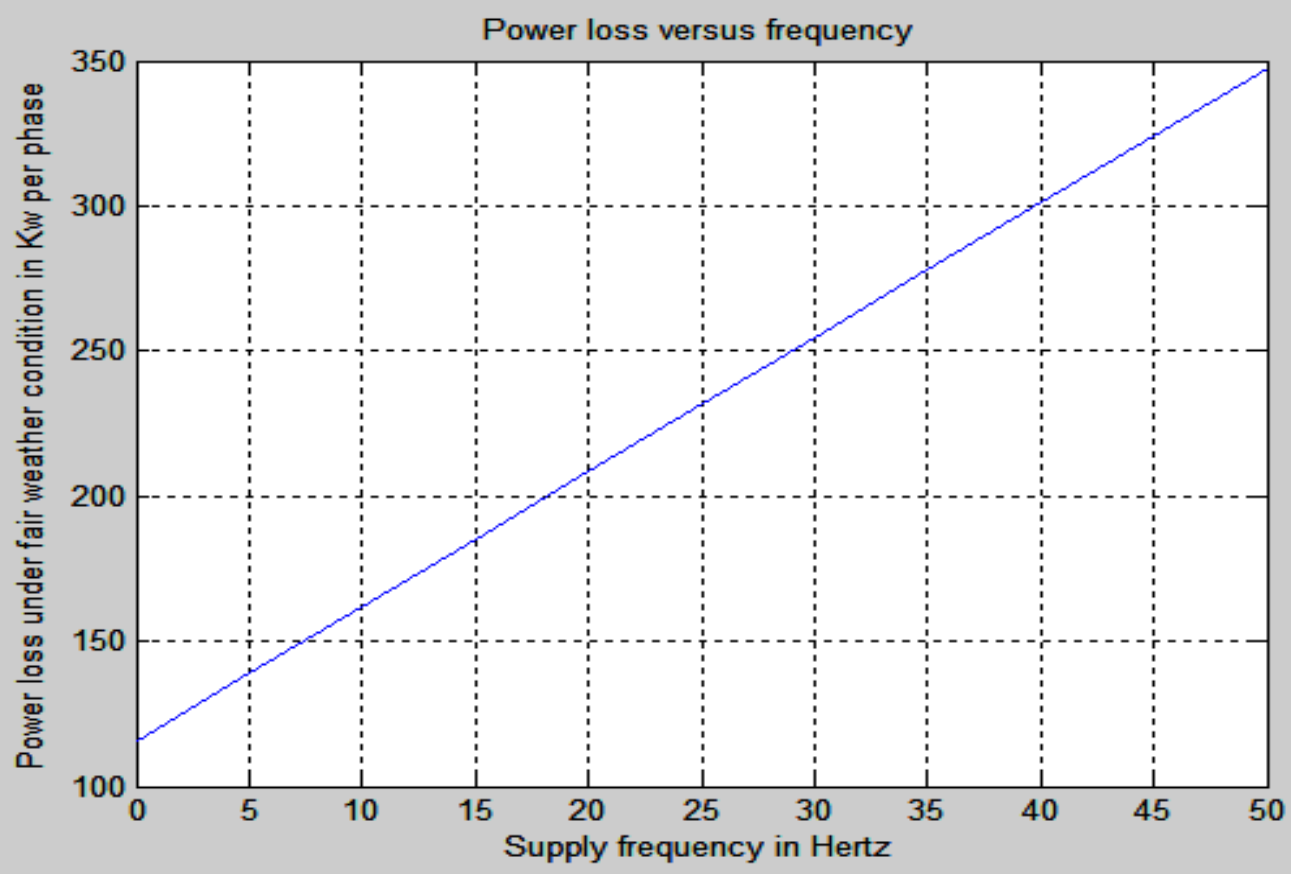

Fig. 3: power loss versus frequency

\subsection{Size of conductor}

Equation 1 shows that corona loss is directly proportional to the square root of the size of conductor.

Figure 4 shows that any increase in conductor diameter leads to corresponding increase in corona loss.

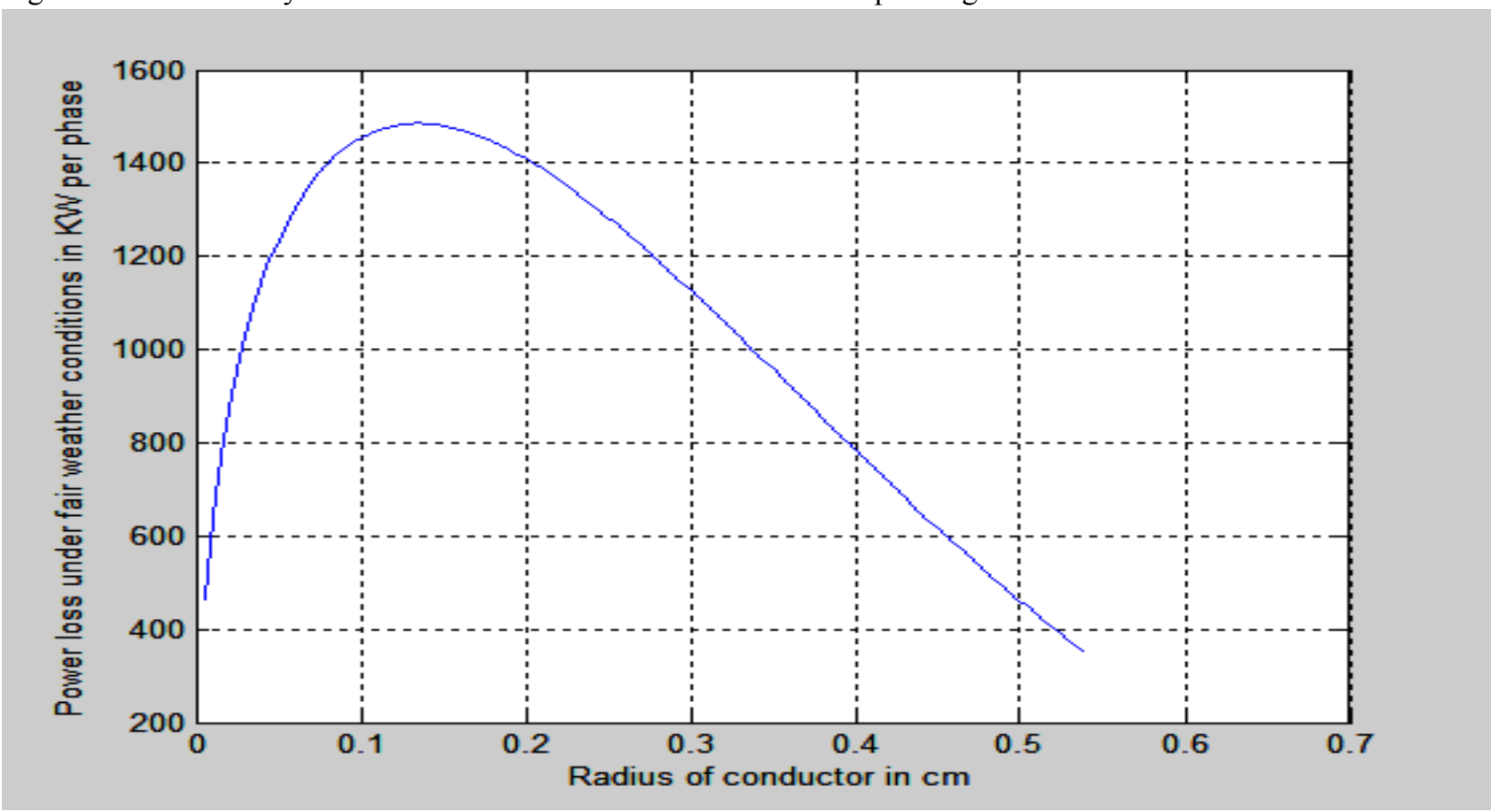

Fig.4: power loss versus size of the conductor

\subsection{Line voltage}

Corona starts for voltages higher than the disruptive critical voltage. The disruptive critical voltage in figure 5 is $55.98 \mathrm{kv}$ to Neutral (Line to line voltage-96.96kv). The higher the supply voltage the larger the corona loss 


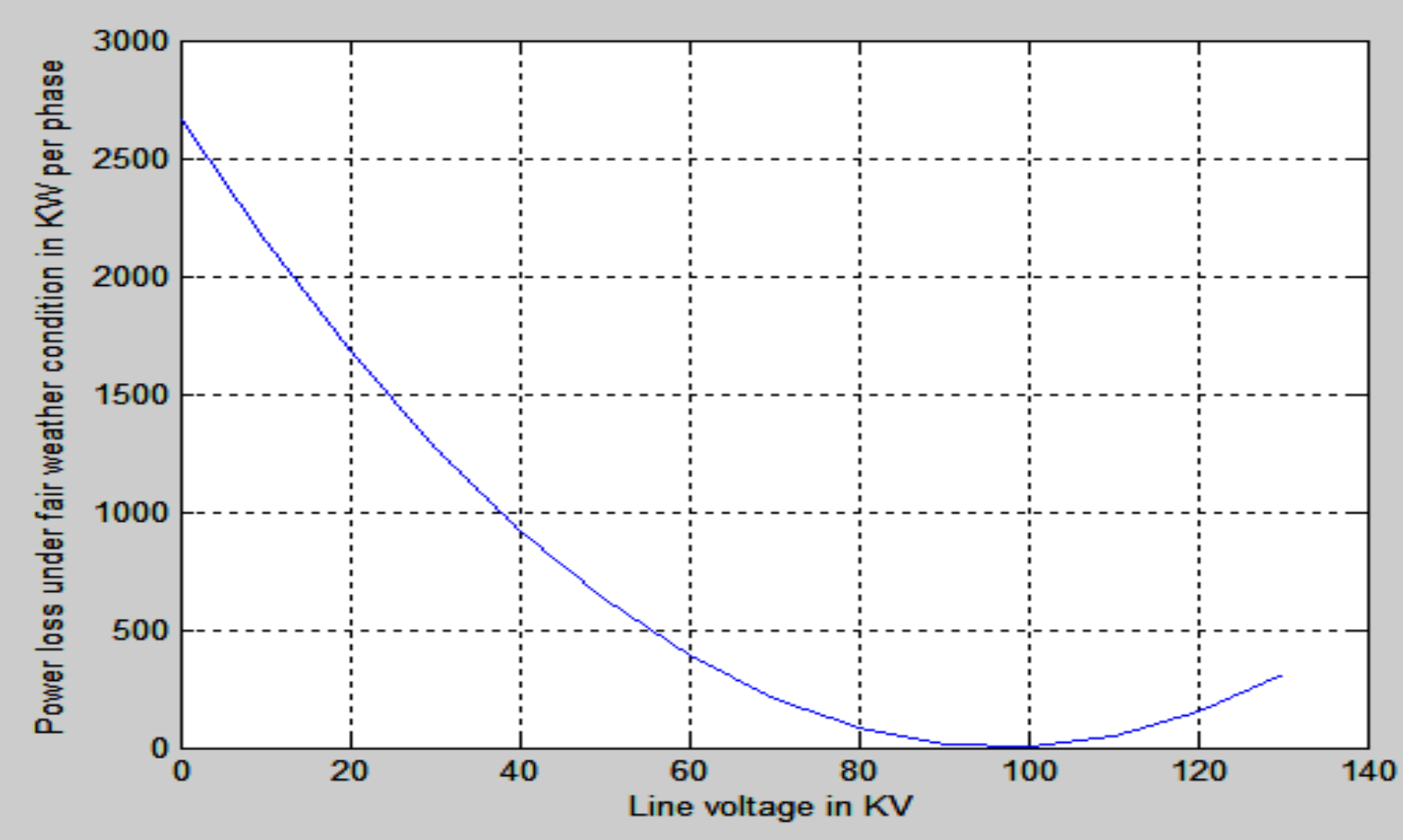

Fig. 5: corona loss versus the line voltage

\section{Stormy And Fair Weather Conditions}

In stormy or bad atmospheric weather conditions like snows, rains and hailstorm reduce disruptive critical voltage and increases the corona effects. Figure 6 shows the graph of corona loss at both the stormy and the fair weather conditions at different values of disruptive critical voltages. The results show that the lower the value of disruptive critical voltage, the higher the power loss due to corona.

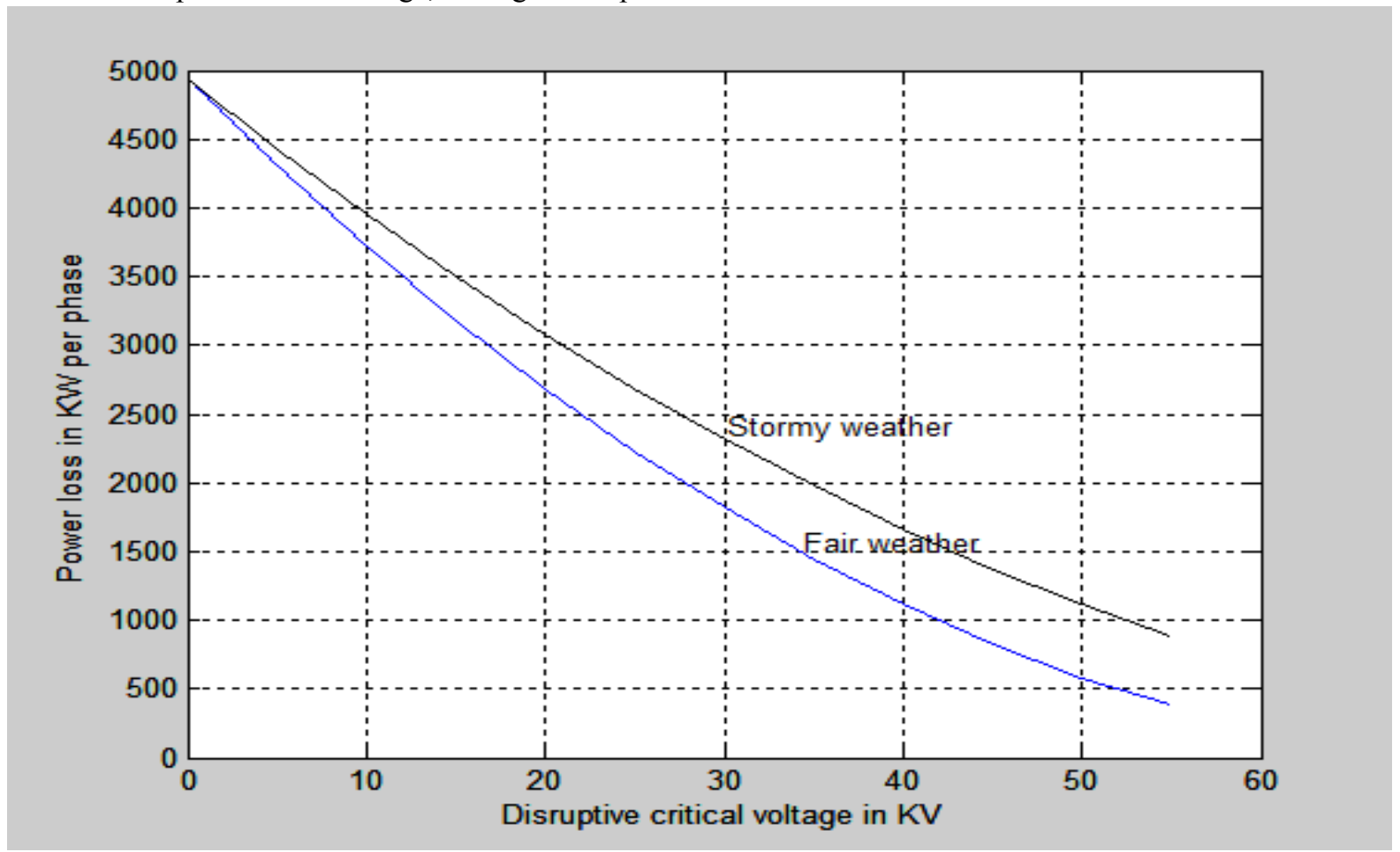

Fig. 6: power loss under stormy and fair weather conditions 


\section{Means Of Reducing Power Loss Due To Corona}

The use of bundle conductors reduce corona loss

Spacing between conductors is selected so that corona is tolerable

$>$ Since the shape of conductors affect corona loss, cylindrical shape conductors have uniform field that reduces corona loss than any other shape

> The voltage stress and electric field gradient should be minimized which can be accomplished by using good high voltage design practices. Using conductors with large radii reduce corona loss

$>$ Void free solid conductors and insulators should be used

$>$ Corona formation can be suppressed, if the terminals on high voltage equipment are designed with smooth round diameter rounded shapes like balls and the addition of corona rings to insulators of high voltage transmission lines

\section{Conclusion}

Using matlab program for the sample analysis, it is found that in wet conditions, the value of corona loss is more than that of the dry season. Underground cables with good insulation design can prevent power loss since this will not be much affected by changing in weather conditions.

\section{References}

[1] Wadwah C. L "Electric Power System," chennai New Age International Publisher Ltd. 2006

[2] Mehta V. K, Mehta R, "Principles of Power System," S. Chand, New Delhi, 2004.

[3] Gupta B. R, "Power system analysis and design," S. Chand, New Delhi, 2007.

[4] Curt Harting (2010). AC Transmission Line Losses.htm

[5] Gupta J. B. A course in power system. New Delhi, 2008

[6] Anumaka (2012). Nigerian 330kv Interconnected Power Systelm

[7] International conference on Large High Voltage Electric System, Interference Produced by Corona Effect on Electric Systems, Paris. 1974.

[8] Leonard Loeb(1965). Electrical Coronas. Their Basic Physical Mechanisms. University of California Press M. Bowles, "State Electricity Profiles 2008," US Energy Information Administration, DOE/EIA0348(01).2010.

[9] Hayt. W and Buck, Engineering Electromagnetics (Mcgraw-Hill,2006). PP346, 486

[10] Instruction Manual 661. "Partial Discharge (Corona) Testing Equipment" Biddle instruments, James G. Biddle Co. Plymouth Meeting, Peninsylvania 19462 